\title{
RESPONSES OF THE INTRA-OCULAR PRESSURE TO DIENCEPHALIC STIMULATION*
}

\author{
BY \\ J. GLOSTER \\ Ophthalmological Research Unit (Medical Research Council), Institute of Ophthalmology, \\ University of London
}

EARLY experimental work on the intra-ocular pressure was concerned mainly with the procedures which cause its elevation or reduction, but more recently attention has been focused upon the factors responsible for the maintenance of normal pressure in the eye. From this second line of thought has developed the concept that the intra-ocular pressure is kept at a fairly constant level by a regulatory mechanism; the evidence for this has been reviewed elsewhere (Gloster, 1959). It has been suggested that regulation may be effected by a purely mechanical system, by hormonal influences, or by a reflex nervous mechanism. Concerning the last possibility, the view that the intra-ocular pressure is controlled by a diencephalic nervous mechanism has received considerable support (Elwyn, 1938; L. Hess, 1945; Magitot, 1949; Thiel, 1952; Duke-Elder, 1957), and the most specific hypothesis which has been advanced attributes this control of the influence of one or more "centres" in the diencephalon (Schmerl and Steinberg, 1950).

As a first step in the examination of these hypotheses, the response of the intra-ocular pressure to electrical stimulation of the diencephalon has been studied (Schmerl and Steinberg, 1950; Nagai, Ban, and Kurotsu, 1951; von Sallmann and Lowenstein, 1955; Gloster and Greaves, 1957).

Gloster and Greaves $(1957,1958)$, working with cats, obtained falls in intra-ocular pressure accompanied by rises in blood pressure, these reactions being obtained from stimulations in an area of the hypothalamus close to the anterior column of the fornix. It was thought that the fall in intraocular pressure was due to vasoconstriction in the eye, since the effect was abolished by preganglionic cervical sympathotomy. From these observations two closely related questions arise. First, can the area of the hypothalamus from which these effects were elicited be considered as a "centre" concerned specifically with reduction of intra-ocular pressure? Secondly, is the vasoconstriction evoked from this area limited to the eye or does it involve other tissues, the blood vessels of which are innervated via the cervical sympathetic trunk?

Gloster and Greaves (1957) also described rises in intra-ocular pressure which were not dependent upon changes in the systemic blood pressure. Most of these responses were obtained from the stimulation of points which were scattered over a fairly wide area of the thalamus. However, it was

* Received for publication 3 June, 1960. 
clear that these rises in intra-ocular pressure were not all of the same type, and it seemed possible that, if they could be divided into homogeneous groups, a definite relationship might be established between each type of rise in intra-ocular pressure and a particular area of the diencephalon.

Lastly, in the earlier work of Gloster and Greaves (1957), diencephalic stimulation often evoked ocular manifestations of sympathetic activity (e.g. pupillary dilatation or retraction of the nictitating membrane), but effects attributable to parasympathetic excitation (e.g. pupillary constriction) were rarely seen. In view of the work of W. R. Hess (1932), it was thought that the characteristics of the electrical stimulus used (rectangular pulses of $1 \mathrm{msec}$. duration at 30 cycles per second) might have favoured the excitation of sympathetic rather than parasympathetic nervous elements, and that therefore any influence of the parasympathetic component of the diencephalon on the intra-ocular pressure would not have been revealed.

The following experiments were undertaken to examine these points.

\section{Methods}

Cats were anaesthetized with chloralose (100 mg./kg. injected intravenously) and the subsequent procedure followed that described by Gloster and Greaves (1957) for recording intra-ocular pressure, femoral arterial pressure, and movements of the nictitating membrane during electrical stimulation of the diencephalon. Modifications of this technique were as follows:

(a) A smaller electrode was used. This consisted of an insulated stainless steel wire $(0.15 \mathrm{~mm}$. O.D.) passed through a stainless steel supporting tube $(0 \cdot 4 \mathrm{~mm}$. O.D.), the outer surface of which was covered with an insulating coating of lacquer. The active tip of the electrode was formed by a bared portion of the inner wire, $1 \mathrm{~mm}$. long, which projected beyond the end of the supporting tube.

(b) Damped electrical pulses having a duration of $12.5 \mathrm{msec}$. were used at a frequency of $8 \mathrm{c} / \mathrm{s}$, the peak voltage being $3 \mathrm{v}$. Their source was a generator of the type described by Attree (1950), with the output modified by a suitable resistance-capacitance combination.

(c) Vascular changes in the skin of the ears were recorded, using a photo-electric method based upon that of Holton and Perry (1951). Each auricle was shaved, and a circular patch, $20 \mathrm{~mm}$. in diameter, on the inner surface of the auricle was illuminated by a 6-volt projection lamp. A photo-cell having a sensitive surface $20 \mathrm{~mm}$. in diameter was placed on the outer surface of each auricle to receive the light projected through the tissues of the ear. Each photo-cell was connected to a mirror galvanometer from which a continuous photographic record was made. A variable resistance was connected in parallel with each mirror galvanometer in such a way as to provide a constant damping resistance, yet allowing the sensitivity of the circuit to be adjusted. The galvanometers were so arranged that a downward movement on the record accompanied an increase in the light received by the photo-cell, indicating a decrease in the amount of blood in the ear; contrariwise, an upward movement of the tracing signified the presence of more blood in the auricular skin. In interpreting the changes in the recordings from the photo-cells, due regard was given to the accompanying change in blood pressure. Thus a downward movement of the tracing occurring with a rise in systemic blood pressure was 
taken to indicate active vasoconstriction in the ear; an upward movement of the tracing under similar circumstances was interpreted as an indication of passive hyperaemia in the ear. Similarly, active vasodilatation in the ear was shown as an upward movement on the photo-cell record in conjunction with a fall in systemic blood pressure.

Finally, the positions of the electrode tracks and the points stimulated were determined by preparing sections of the brain which were stained with haematoxylin and eosin. The results were plotted on maps of frontal sections of the diencephalon which were adapted from the atlas of Jasper and Ajmone-Marsan (1955).

\section{Results}

(A) Responses of Intra-ocular Pressure to Diencephalic Stimulation

This account is based upon the results of 977 stimulations in 35 cats, and the frequency of the responses of the intra-ocular pressure can be summarized as follows. In about 17 per cent. of the stimulations there was a fall in intra-ocular pressure, in about 38 per cent. of stimulations a rise, and in the remaining stimulations no significant response.

It was apparent that division of the responses of the intra-ocular pressure into falls and rises was only the first step in the analysis of the results; each of these groups could be sub-divided further, either according to certain characteristics of the response of the intra-ocular pressure or according to the relationship of the latter to accompanying effects.

(In the following account, the eye on the same side of the mid-line as the stimulating electrode is called the "ipsilateral eye"; the opposite eye is referred to as the "contralateral eye".)

(a) Falls in Intra-ocular Pressure.-These were divided into (i) parallel, (ii) independent, and (iii) abrupt falls. In a few stimulations, there were falls in intra-ocular pressure which could not be classified with certainty.

(i) Parallel Falls.-These were accompanied by a fall in systemic blood pressure and were regarded as direct consequences of the latter. The pressure in the eye and the blood pressure ran strictly parallel to one another. Such responses were relatively uncommon, being found in about 3.5 per cent. of the total number of stimulations.

(ii) Independent Falls.-These occurred in about 5.5 per cent. of the stimulations and were of far greater interest, since they were not dependent upon a fall in systemic blood pressure, and occurred as components of a highly characteristic response pattern which in its complete form consisted of the following:

(1) A fall in pressure in one or both eyes.

(2) A rise in blood pressure.

(3) Bilateral pupillary dilatation.

(4) Retraction of one or both nictitating membranes.

(5) Vasoconstriction in the skin of the ear. 
Pupillary dilatation and cutaneous vasoconstriction occurred in about 90 per cent. of the responses; the least constant feature of the response pattern was retraction of the nictitating membranes, which was present in only about 30 per cent. of responses showing an independent fall in intra-ocular pressure. Preganglionic division of the cervical sympathetic trunk abolished independent falls (Fig. 1).

\section{CAT GI}
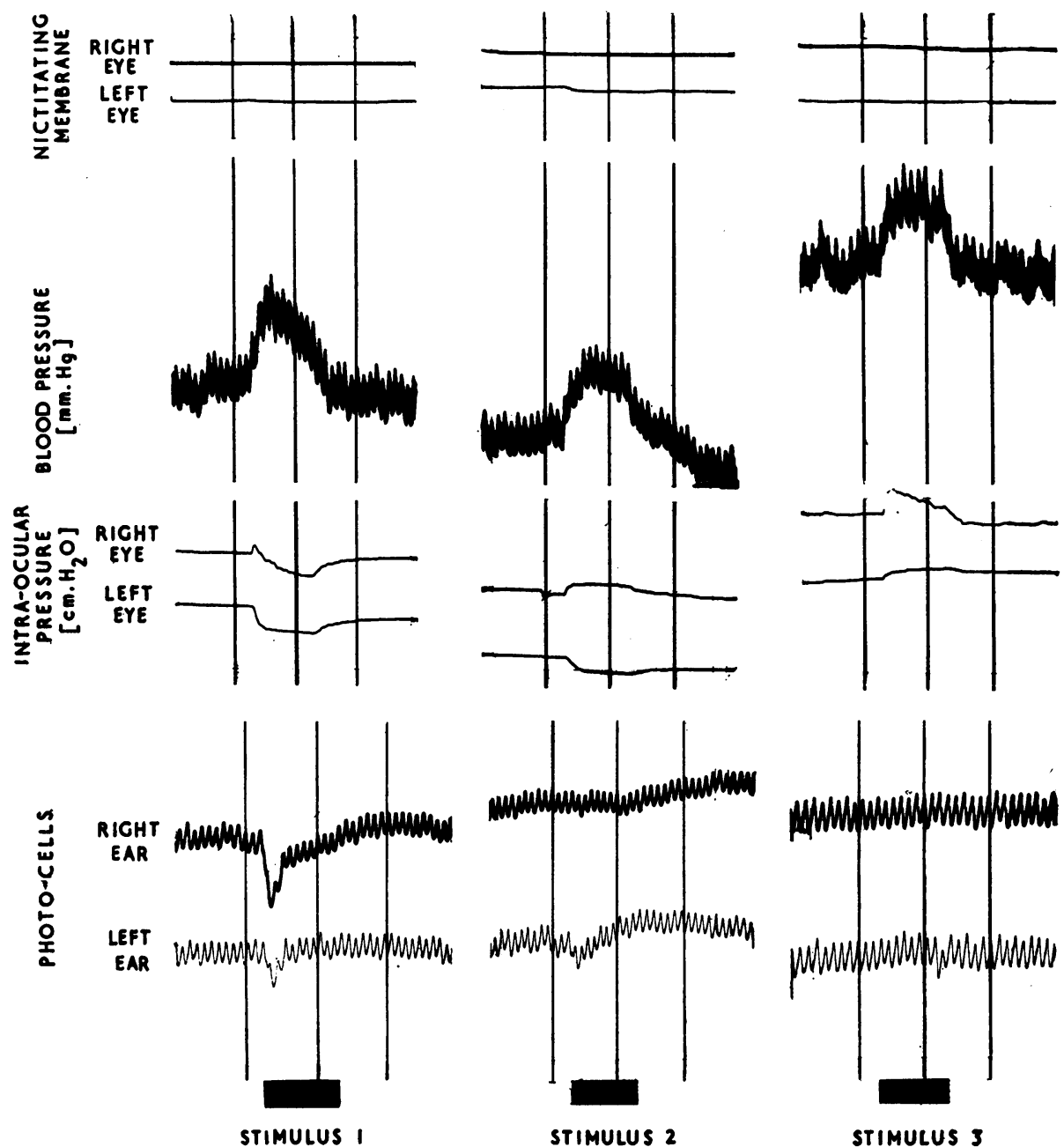

STIMULUS 3

FIG. 1.-Effect of preganglionic cervical sympathotomy on independent falls in intra-ocular pressure. In this and succeeding records, the interval between consecutive vertical lines represents a period of $60 \mathrm{sec}$.

The tip of the stimulating electrode was $12 \mathrm{~mm}$. anterior to the inter-aural line, $3 \mathrm{~mm}$. to the right of the mid-line, and $0.5 \mathrm{~mm}$. above the upper border of the anterior column of the fornix. 
The effects of three successive stimulations of the same point in the hypothalamus are illustrated; the tip of the electrode was $12 \mathrm{~mm}$. in front of the inter-aural line, $3 \mathrm{~mm}$. to the right of the mid-line, and slightly above the level of the anterior column of the fornix. The response to the first stimulation consisted of a rise in blood pressure, bilateral reduction of intra-ocular pressure, bilateral pupillary dilatation, and vasoconstriction in the skin of both ears (shown as downward movements of the photo-cell recordings); the typical response pattern was thus complete apart from retraction of the nictitating membrane. The right sympathetic trunk was then divided and, in the subsequent stimulation, there was no fall in pressure in the right eye and no vasoconstriction in the right ear. Immediately after the second stimulation, the left cervical sympathetic trunk was divided and, in the subsequent stimulation, neither eye showed a reduction in pressure and vasoconstriction was absent in the skin of the ears. Three other experiments gave similar results; in one of these, retraction of the nictitating membrane occurred in the initial response but was eliminated by cervical sympathotomy.

(iii) Abrupt Falls.-These occurred in about 5 per cent. of the total number of stimulations and could be differentiated clearly from the independent falls just described. As the term "abrupt fall" suggests, the first distinguishing feature was that the fall in intra-ocular pressure was rapid, the lowest level being reached within 5 seconds of starting the stimulation, whereas the independent fall in intra-ocular pressure was not complete until about 15 seconds after starting the stimulation. Secondly, a very small but definite ocular movement accompanied almost half the abrupt falls. Thirdly, 80 per cent. of abrupt falls were accompanied by a slight relaxation of the nictitating membrane which was shown as a downward movement of the corresponding photographic record. Lastly, abrupt falls in intra-ocular pressure could still be obtained after preganglionic cervical sympathotomy.

(b) Rises in Intra-ocular Pressure.-These were divided into (i) parallel, (ii) muscular, (iii) fast, (iv) independent, and (v) slow rises. A few responses could not be classified.

(i) Parallel Rises.-These depended upon concomitant rises in the systemic blood pressure. They were found in about 22 per cent of the total number of stimulations. The rises in intra-ocular pressure and blood pressure ran strictly parallel courses, but the vascular responses in the skin of the ears were variable. Sometimes the record from the photo-cells ran parallel with the tracings of the blood pressure and intra-ocular pressure; that is to say, there was an indication of an increase in the amount of blood in the tissues of the ears; taken in conjunction with the rise in blood pressure, this vascular reaction was interpreted as a passive hyperaemia. In other stimulations, the movement of the photo-cell record was in the opposite 
direction, indicating active vasoconstriction in the tissues of the ear. 70 per cent. of parallel rises in intra-ocular pressure were accompanied by active vasoconstriction in the ear, 17 per cent were accompanied by passive hyperaemia in the ear, and in the remainder the vascular reaction was indefinite.

(ii) Muscular Rises.-In a few stimulations there was a slight oscillation of the eye, the lids, or the nictitating membrane, together with a small rise in intra-ocular pressure. The latter was called a "muscular" rise in intraocular pressure because it was reasonable to assume that the increase in the pressure in the eye was a consequence of external pressure on the globe from neighbouring muscles.

(iii) Fast Rises.-These proved to be of particular interest. Many of these rises were accompanied by rises in systemic blood pressure but could not be considered dependent upon the latter for two main reasons: first, the rise was rapid, the highest level of intra-ocular pressure being reached before the peak of the blood pressure (Fig. 2), and, secondly, the rise was frequently greater than would be expected from the rise in blood pressure.

CAT 4

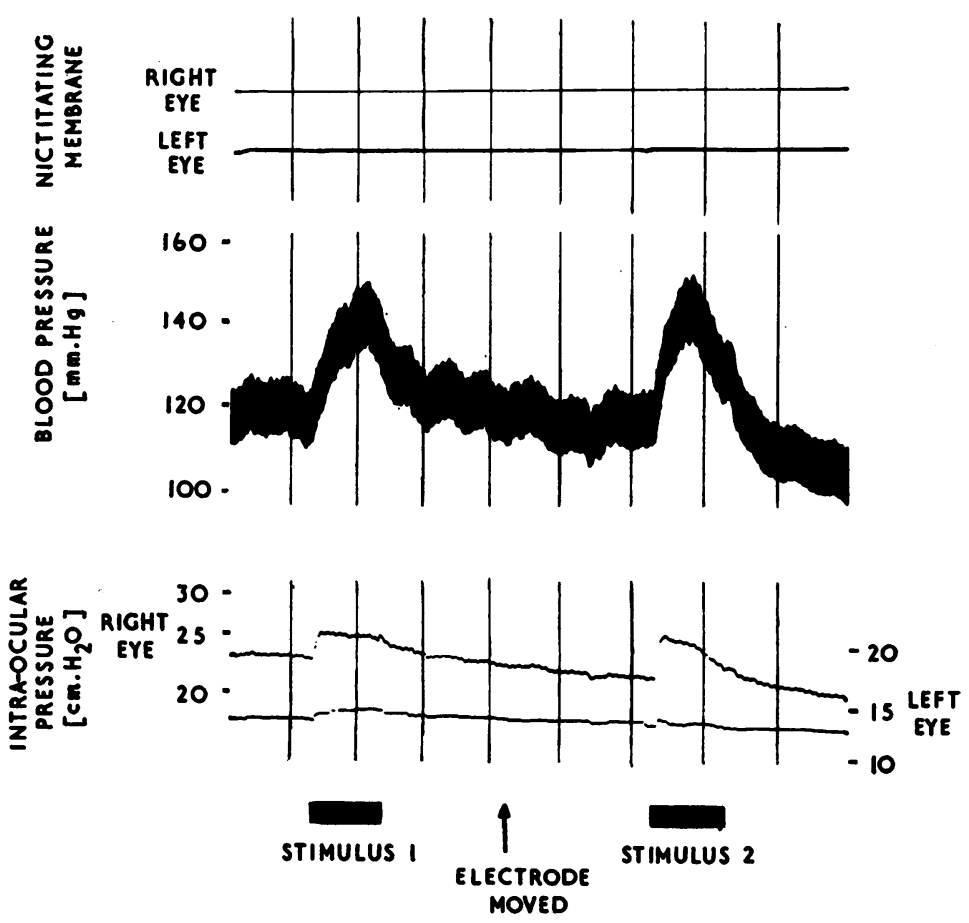

Fig. 2.-Fast rises in intra-ocular pressure.

For Stimulus 1, the tip of the electrode was $12 \mathrm{~mm}$. anterior to the inter-aural line, $2 \mathrm{~mm}$. to the right of the mid-line, and $1.5 \mathrm{~mm}$. above the upper border of the anterior column of the fornix. At $\mathrm{E}$, the electrode was moved $1 \mathrm{~mm}$. downwards for Stimulus 2. 
Fig. 3 illustrates four other features of this response:

(1) The fast rise is much more marked in the ipsilateral (left) eye than in the contralateral eye;

(2) It is sometimes accompanied by a fall in systemic blood pressure;

(3) There is no evidence of vasodilatation in the skin of the ear as shown by the downward movement of the photo-cell tracing;

(4) Repetition of stimulation after an interval of 5 minutes gave a much smaller rise in pressure in the eye; in order to obtain an undiminished rise it was necessary to prolong the interval between stimulations to 15-20 minutes.

\section{CAT 70}
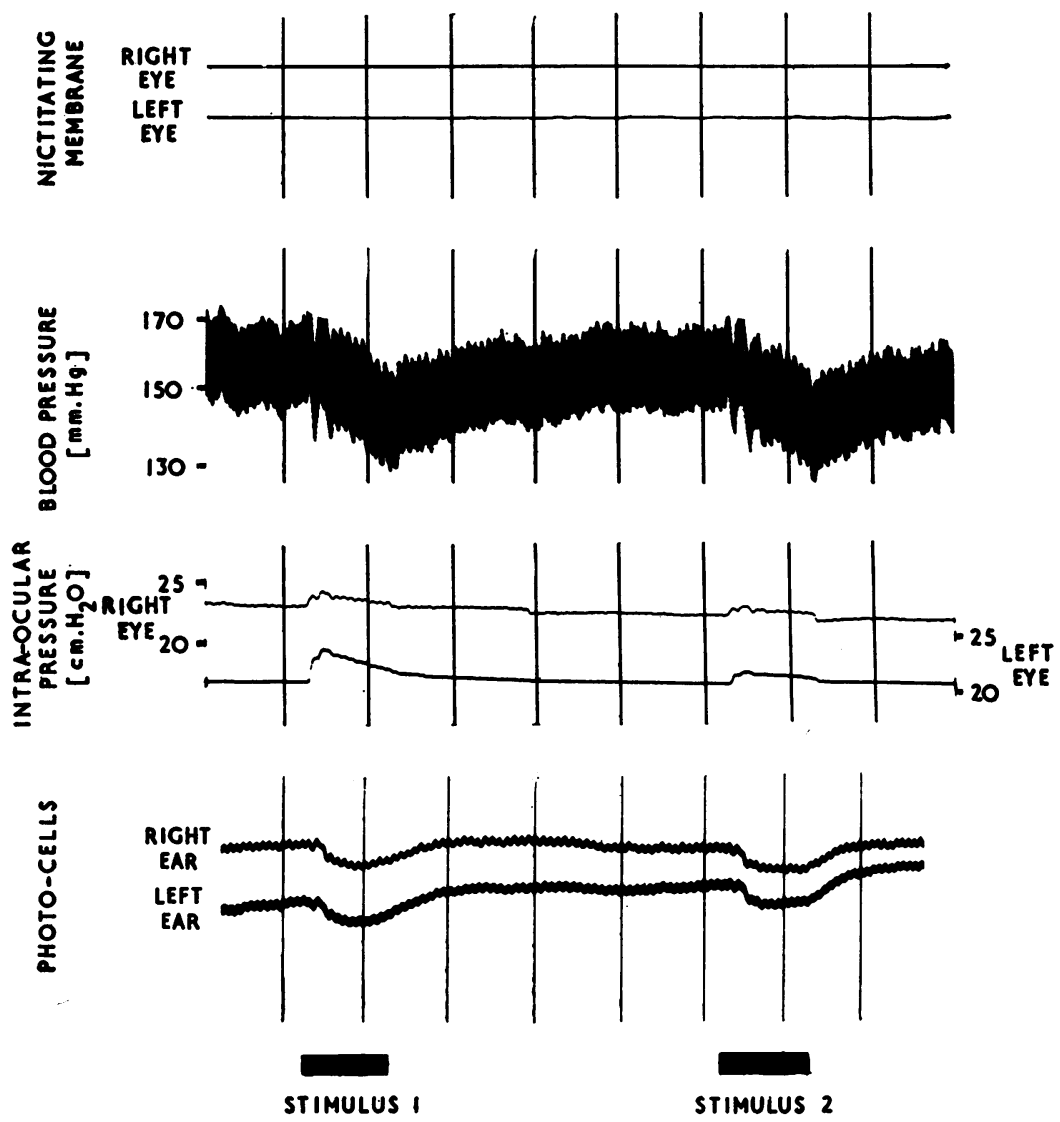

FIG. 3.-Fast rises in intra-ocular pressure.

For both stimuli the tip of the electrode was $13 \mathrm{~mm}$. anterior to the inter-aural line, $2.5 \mathrm{~mm}$. to the left of the mid-line, and $0.5 \mathrm{~mm}$. above the lower border of the anterior column of the fornix. 
There was never the slightest evidence of ocular movement nor of any other muscular activity near the eye. Also, fast rises in intra-ocular pressure were unaffected by cervical sympathotomy and excision of the superior cervical ganglion.

In view of these observations, a vascular causation was suspected and this possibility was investigated as follows. In the same animal, three types of rises in intra-ocular pressure were studied:

(1) "Muscular" rises, obtained by stimulating a branch of the facial nerve to the orbicularis oculi;

(2) "Vascular" rises, obtained by releasing a clamp applied to the common carotid artery $60 \mathrm{sec}$. previously;

(3) Fast rises, obtained by diencephalic stimulation.

The level of pressure in the eye was adjusted by connecting a saline reservoir directly to the pressure-recording system for a few seconds and the effect of varying the initial level of intra-ocular pressure upon the magnitude of "muscular", "vascular", and fast rises was observed. The results of one experiment are shown in Fig. 4.

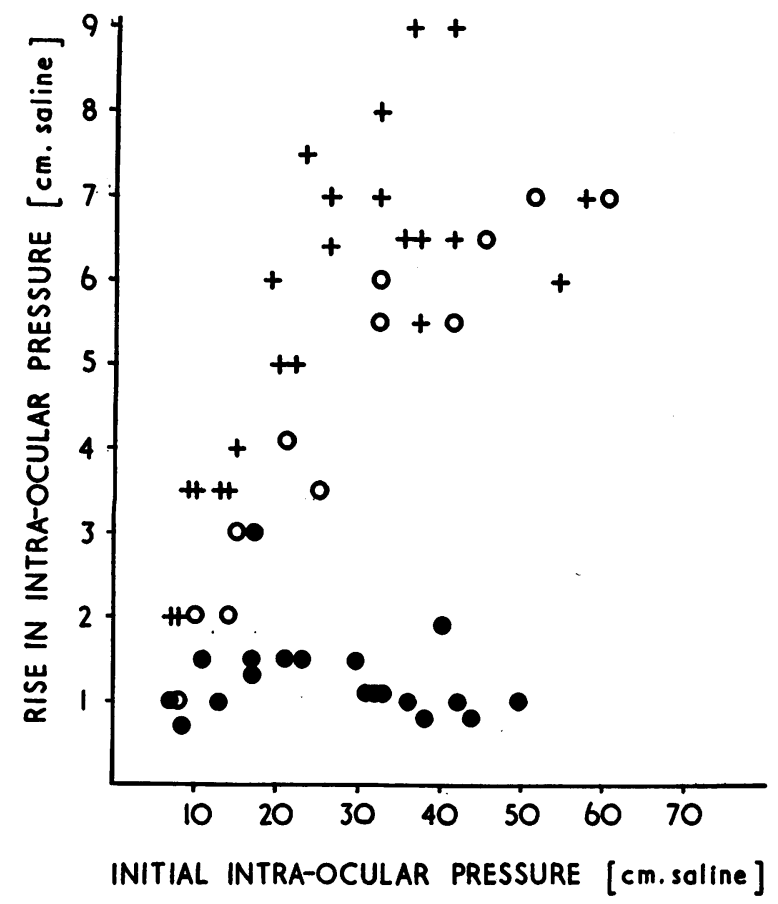

Fig. 4.-Variation of muscular,"vascular", and fast rises in intraocular pressure with initial pressure.

$\mathrm{O}=$ "Vascular" rises on discontinuing carotid occlusion.

= Muscular rises on stimulating nerve to orbicularis oculi muscle.

$+=$ Fast rises in response to diencephalic stimulation. 
Rises in intra-ocular pressure due to external muscular pressure do not vary markedly with the initial pressure in the eye, while rises due to a sudden increase in the arterial supply to the eye increase greatly in magnitude as the initial intra-ocular pressure increases; the variation of fast rises with the initial level of intra-ocular pressure resembles that of the "vascular" rises and not that of the "muscular" rises. Similar results were obtained in two other experiments.

(iv) Independent Rises.-These were accompanied by a steady or diminishing blood pressure. The rise of pressure in the eye never exceeded $5 \mathrm{~cm}$. of saline, but, unlike the fast rises, this effect remained constant in its magnitude during stimulation and was equal in the two eyes. Judged from the photographic record alone, independent rises appeared similar to some of the muscular rises in intra-ocular pressure, but there was never the slightest evidence of any muscular activity in the region of the eye. These independent rises were not often encountered when the stimulating current had the characteristics usually employed in this study, i.e. damped pulses of $12.5 \mathrm{msec}$. duration at a frequency of $8 \mathrm{c} / \mathrm{s}$; they became more evident when rectangular pulses of $1 \mathrm{msec}$. duration at a frequency of $30 \mathrm{c} / \mathrm{s}$ were used. The vascular reactions in the skin of the ears were usually insignificant. Fig. 5 (overleaf) shows independent rises in intra-ocular pressure and illustrates some of the features mentioned above.

(v) Slow Rises.-These were so named because the maximum rise in pressure was reached only at the conclusion of the $60 \mathrm{sec}$. period of stimulation. Slow rises, although small in magnitude and uncommon, were of some interest because they were accompanied by an unchanged or falling blood pressure together with an increase in the blood content of the ears, suggesting that there was active vaso-dilatation in these tissues.

Pupillary dilatations were obtained from many areas of the diencephalon, as in earlier studies. Pupillary constrictions were occasionally obtained from the extreme anterior portion of the hypothalamus, $15 \mathrm{~mm}$. anterior to the inter-aural line and 1-2 $\mathrm{mm}$. above the optic chiasma, but they were not regularly associated with any particular type of response of the intra-ocular pressure.

(B) Localization in the Diencephalon of the Points from which Responses of the InTRA-OCular Pressure Were Elicited

In the majority of experiments described in the preceding section, the electrode tracks were identified satisfactorily in the histological preparations, and 855 points with their corresponding responses could be plotted on maps of the diencephalon. The points stimulated were distributed fairly evenly throughout the diencephalon in frontal planes 8 to $15 \mathrm{~mm}$. anterior to the 
CAT 55
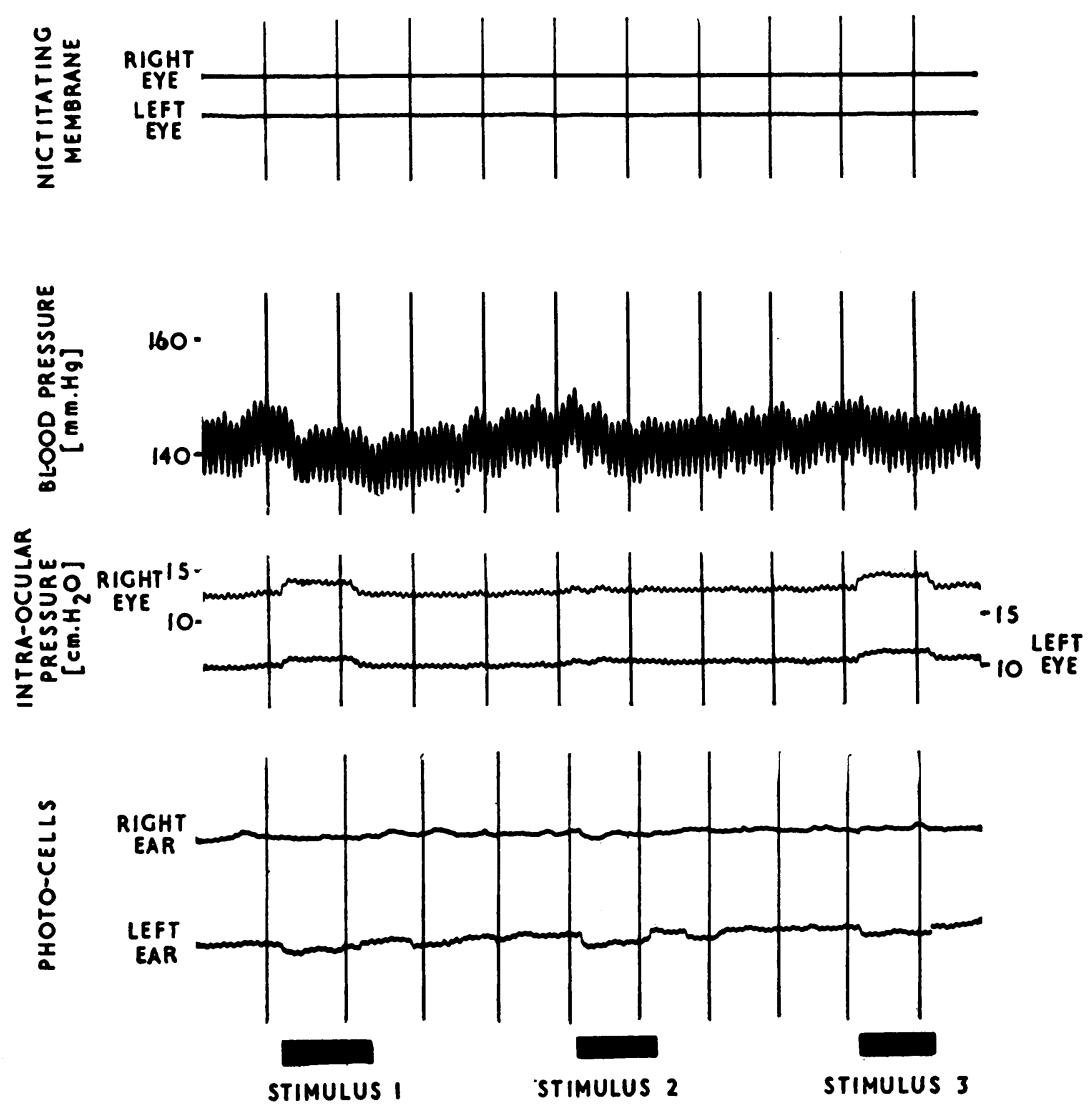

FIG. 5.-Independent rises in intra-ocular pressure.

Stimuli 1 and 3 with rectangular pulses of $1 \mathrm{msec}$. duration at $30 \mathrm{c} / \mathrm{s}$.

Stimulus 2 with damped pulses of $12.5 \mathrm{msec}$. duration at $8 \mathrm{c} / \mathrm{s}$.

For all three stimuli, the tip of the electrode was $9 \mathrm{~mm}$. anterior to the inter-aural line, and $1 \mathrm{~mm}$. to the right of the mid-line at the lower border of the thalamus.

inter-aural line, and extending from the mid-line for a distance of about $6 \mathrm{~mm}$. laterally.

The points from which rises in blood pressure were obtained occurred most frequently in the posterior part of the hypothalamus, while the points yielding falls in blood pressure were more commonly found in the anterior regions; nevertheless, there was considerable intermingling of points giving the two types of reaction. Consequently, the points yielding parallel rises and parallel falls in intra-ocular pressure were scattered similarly throughout the diencephalon.

With regard to the other reactions of the intra-ocular pressure, it can be said that the points from which a particular response was elicited were neither 
scattered randomly throughout the whole diencephalon nor limited to small circumscribed areas.

For example, almost 90 per cent. of the points yielding independent falls in intra-ocular pressure were located in the hypothalamus, and none was more than $13 \mathrm{~mm}$. anterior to the inter-aural line; however, within this part of the hypothalamus, the points showed no clear grouping apart from a possible concentration in an area extending for about $1.5 \mathrm{~mm}$. around the anterior column of the fornix. Also, many points within this relatively large hypothalamic area were stimulated and did not yield independent falls in intra-ocular pressure. The distribution of points giving independent falls in intra-ocular pressure in a frontal plane $11 \mathrm{~mm}$. anterior to the inter-aural line is shown in Fig. 6.

\section{A II}

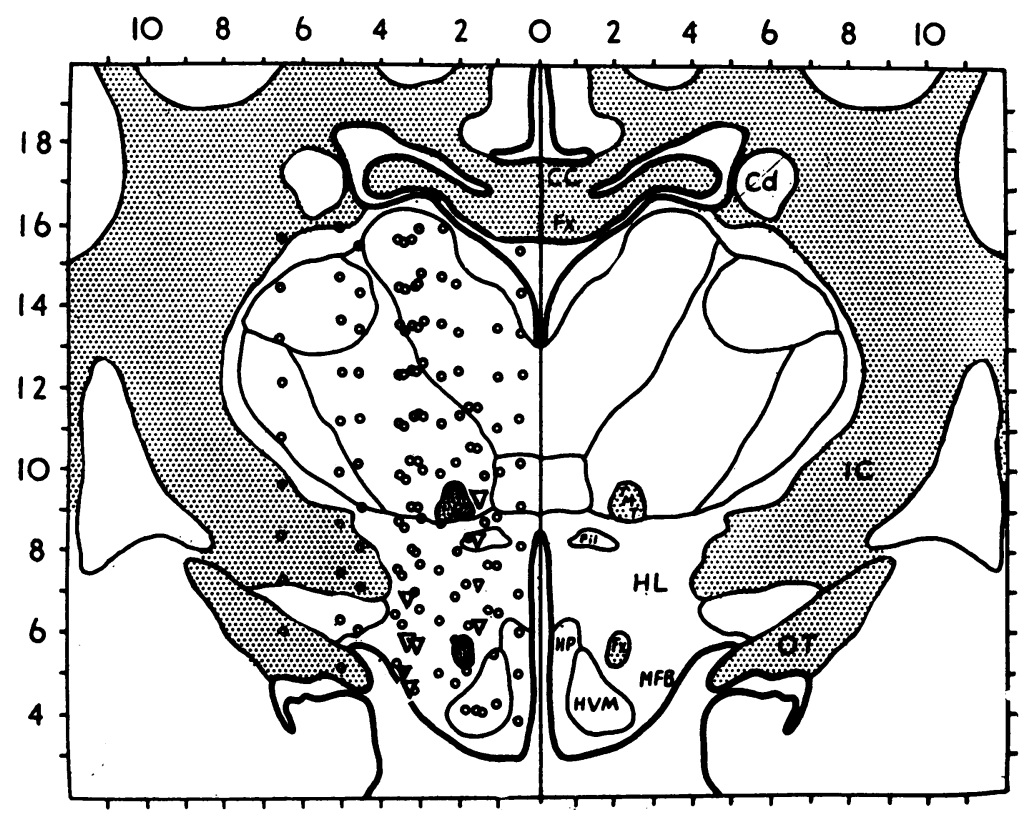

FIG. 6.-Localization of points giving independent falls in pressure in the ipsilateral eye in a frontal plane $11 \mathrm{~mm}$. anterior to the inter-aural line.

$\nabla$ Points giving rise in blood pressure together with fall in intra-ocular pressure.

Points giving above response together with retraction of nictitating membrane.

Points not giving the above responses.
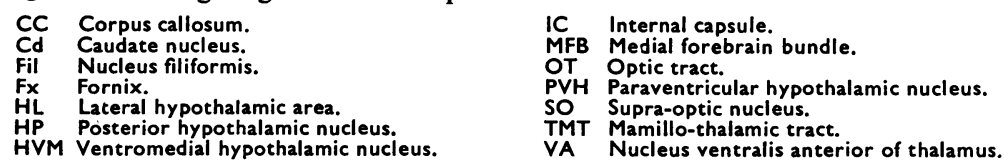

Abrupt falls in intra-ocular pressure were obtained from points which were scattered widely throughout the diencephalon but did not lie more than $12 \mathrm{~mm}$. anterior to the inter-aural line. Most of these points were located 
in a frontal plane $8 \mathrm{~mm}$. anterior to the inter-aural line, i.e. at the caudal limit of the region studied.

Muscular rises in intra-ocular pressure were elicited predominantly from points in or close to the internal capsule and from points in the posterior hypothalamus and subthalamus.

Fast rises in intra-ocular pressure were elicited from a fairly localized area. The most anterior points yielding this response were in a plane $13 \mathrm{~mm}$. in front of the inter-aural line and lay dorsally and laterally to the anterior column of the fornix. At distances of 11 and $12 \mathrm{~mm}$. anterior to the interaural line they formed a group lying dorsal to the anterior column of the fornix as shown in Fig. 7.

A 12

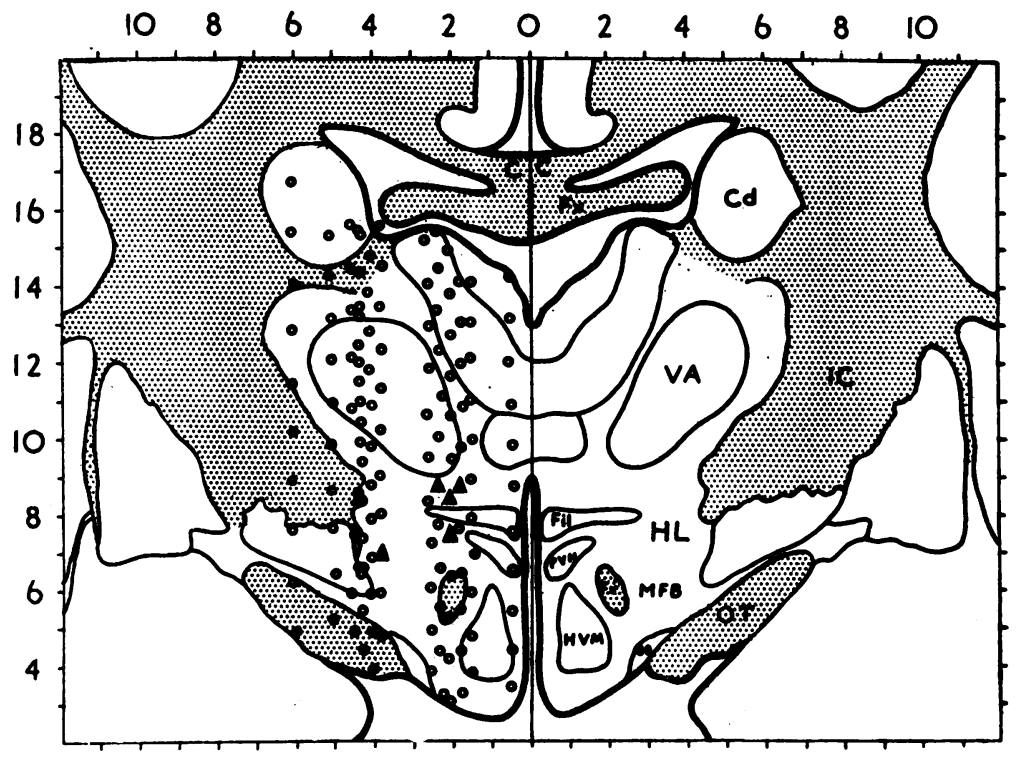

FIG. 7.-Localization of points giving fast rises in pressure in the ipsilateral eye in a frontal plane $12 \mathrm{~mm}$. anterior to the inter-aural line.

$\Delta$ Points giving fast rises in intra-ocular pressure.

$\bigcirc$ Points not giving this response.
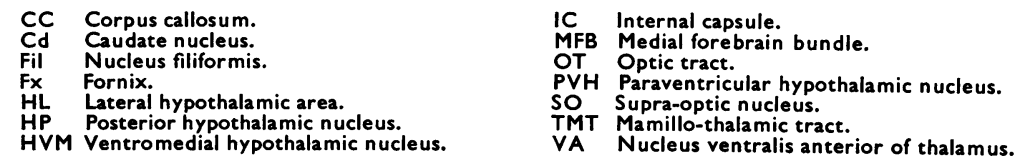
Traced caudally, other points were found as far back as the posterior limit of the area investigated but their distribution became more scattered.

Independent rises in intra-ocular pressure were obtained from stimulations in planes up to $11 \mathrm{~mm}$. anterior to the inter-aural line, the points yielding these responses being almost always in the thalamus and extreme dorsal regions of the hypothalamus and subthalamus.

Slow rises in intra-ocular pressure were elicited mainly from points in planes 13 to $15 \mathrm{~mm}$. anterior to the inter-aural line. Although showing a slight tendency to be more frequent in the lateral parts of the pre-optic region and anterior hypothalamus, these points showed no distinct grouping.

\section{Discussion}

When these results are considered in relation to the regulation of intraocular pressure, it is clear that those responses of the intra-ocular pressure which were merely reflections of changes in systemic blood pressure or which were caused by muscular pressure on the eye are of no significance. Parallel rises and parallel falls in intra-ocular pressure were clearly reflections of concomitant changes in systemic blood pressure. Abrupt falls in intra-ocular pressure, which were accompanied very frequently by visible ocular movement or by relaxation of the nictitating membrane, must be attributed to some change in the tone of the extra-ocular muscles, while the so-called "muscular" rises are to be regarded as the results of external pressure on the globe. When such reactions are eliminated, there remain as possible manifestations of a regulatory system the independent falls, and the fast rises, independent rises, and slow rises in intra-ocular pressure.

An essential requirement of any component of a regulatory system is that it should be capable of producing a sustained alteration in pressure. In these experiments the emphasis was upon topographical considerations and it was necessary to use stimuli of relatively brief duration $(60 \mathrm{sec}$.) in order to make practicable the exploration of the whole diencephalon. Therefore it is impossible to judge directly from these results whether any of the reactions enumerated above is sufficiently persistent to contribute to the regulation of intra-ocular pressure.

In the case of the independent falls in intra-ocular pressure, however, there is some reason for believing that these could represent part of a controlling system, because it could be shown that the fall in pressure in the eye was mediated via the cervical sympathetic trunk. Greaves (1958) found that stimulation of the cervical sympathetic trunk for a period of half an hour caused a persistent reduction in intra-ocular pressure, and it is reasonable to conclude that excitation of the same nerve resulting from hypothalamic activity could also produce a persistent depression of intra-ocular pressure.

It is less certain whether fast rises, independent rises, and slow rises in intra-ocular pressure represent components of a regulatory system. Again 
the periods of stimulation were too short to show whether these reactions gave sustained alterations in intra-ocular pressure. At the present moment it can only be said that there exist diencephalic pathways which are concerned with ocular vasodilatation and, if their influence extended to the blood vessels of the ciliary processes, then a persistent increase in intra-ocular pressure could result from diencephalic influences.

If mechanisms which regulate intra-ocular pressure are present in the diencephalon, then it would be expected that they would influence intraocular pressure only and that they would have no significant effect upon other parts of the organism. It was found that independent falls in intra-ocular pressure were frequently accompanied by rises in systemic blood pressure and by vasoconstriction in the skin of the ears. In view of these widespread systemic effects, it is inconceivable that this reaction, as a whole, forms part of a regulatory system for intra-ocular pressure. The same argument applies to fast rises, independent rises, and slow rises in intra-ocular pressure, which were commonly accompanied by alterations in systemic blood pressure. The question arises, therefore, whether such changes in intra-ocular pressure can occur as isolated events during diencephalic stimulation. In this series of experiments, small independent falls in intra-ocular pressure with vasoconstriction in the ear and without an accompanying rise in blood pressure occurred in only two responses and it is felt that little significance can be attached to these. It has been shown elsewhere (Gloster, 1959) that, under the experimental conditions described, the area of nervous tissue stimulated effectively extended for about $1 \mathrm{~mm}$. from the tip of the electrode. Therefore, one cannot rule out completely the possibility that nervous elements exist in the diencephalon which are concerned specifically with ocular vasoconstriction, but that they are intermingled diffusely with other nervous pathways mediating vasconstriction in other tissues.

With regard to fast rises, independent rises, and slow rises in intra-ocular pressure, the position is even less clear, although, bearing in mind the inconstancy of the accompanying changes in blood pressure and of the cutaneous vascular reactions, a similar argument could be advanced for the existence in the diencephalon of nervous pathways which mediate rises in intra-ocular pressure.

Regarding the general hypothesis that the intra-ocular pressure is controlled by a diencephalic nervous mechanism, the only conclusion to be drawn from the results of the present experiments is that the findings are compatible with this view. However, a definite conclusion can be reached with regard to the more specific hypothesis that control of intra-ocular pressure is effected by "centres" in the diencephalon. The only reasonable interpretation to be placed on the term "centre" is that of a relatively small circumscribed anatomical area which is concerned specifically with either reduction or elevation of pressure, although none of the supporters of the specific hypothesis, while freely using the word "centre", has defined it 
precisely. Accepting the definition just given, it is clear that the area from which independent falls in intra-ocular pressure were elicited is too large to be considered as a "centre", especially as it was found that stimulation in this area did not invariably evoke a fall in pressure in the eye. The same is true regarding the areas from which rises in intra-ocular pressure were obtained; although division of these rises into homogeneous groups enabled a closer correlation to be made between the diencephalic area stimulated and a particular type of rise in intra-ocular pressure, none of these areas was sufficiently small and circumscribed to justify the use of the term "centre". It must be concluded that these experiments have failed to demonstrate the existence in the diencephalon of any areas specifically concerned with elevation or reduction in pressure in the eye, and therefore the hypothesis that the intra-ocular pressure is controlled by diencephalic "centres" must be rejected. Since it is impossible, on the basis of the present work, to reject the general hypothesis of diencephalic control of intra-ocular pressure, the possibility remains that such control is effected by a diffuse network of nervous elements distributed throughout the thalamus and hypothalamus.

\section{Summary}

(1) The diencephalon was stimulated in anaesthetized cats and the responses of the intra-ocular pressure and blood pressure, vascular reactions in the skin of the ears, and movements of the nictitating membranes were recorded.

(2) Falls in intra-ocular pressure during diencephalic stimulation could be divided into:

(i) Parallel falls, in which the pressure in the eye followed a course parallel to a fall in the systemic blood pressure.

(ii) Independent falls, in which the pressure in the eye fell despite a concomitant rise in the blood pressure.

(iii) Abrupt falls, due to a change in the tone of the extra-ocular muscles.

(3) Rises in intra-ocular pressure during diencephalic stimulation could be divided into:

(i) Parallel rises, which reflected concomitant rises of the systemic blood pressure.

(ii) Muscular rises, due to increased pressure of the extra-ocular muscles on the globe.

(iii) Fast rises, which were frequently accompanied by but not dependent upon a rise in the blood pressure.

(iv) Independent rises, which were associated neither with rises in blood pressure nor with extra-ocular muscular activity.

$(v)$ Slow rises, which were often accompanied by a fall in blood pressure. 
(4) In general, each type of response of the intra-ocular pressure was elicited from a particular area of the diencephalon, but none of these areas was small or circumscribed. There was considerable overlapping of areas giving different types of response. Also, stimulation in any one of these areas did not invariably give the response characteristic for that area.

(5) The results are discussed in relation to the central nervous regulation of intra-ocular pressure. While the findings are compatible with the general hypothesis that the intra-ocular pressure is under diencephalic control, they are at variance with the specific hypothesis that such control is effected by "centres" in the diencephalon.

\section{REFERENCES}

ATTREe, V. H. (1950). J. sci. Instrum., 27, 43.

DUKE-ELDER, S. (1957). Trans. ophthal. Soc. U.K., 77, 205.

ELWYN, H. (1938). Arch. Ophthal. (Chicago), 19,986.

Gloster, J. (1959). “The Control of Intra-ocular Pressure". Ph.D. Thesis, Univ. London. and GREAVES, D. P. (1957). Brit. J. Ophthal., 41, 513.

(1958). Ibid., 42, 385.

Greaves, D. P. (1958). Personal communication.

HESS, L. (1945). Arch. Ophthal. (Chicago), 33, 392.

Hess, W. R. (1932). "Beitrăge zur Physiologie des Hirnstammes. Vol. 1, Die Methodik der lokalisierten Reizung und Ausschaltung subkortikaler Hirnabschnitte", pp. 29-43. Thieme, Leipzig.

Holton, P., and PerRY, W. L. M. (1951). J. Physiol. (Lond.), 114, 240.

JASPER, H. H., and AJMONE-MARSAN, C. (1955). "A Stereotaxic Atlas of the Diencephalon of the Cat". Nat. Res. Counc. Canada Ottawa.

MAGitor, A. (1949). Arch. Ophtal., n.s. 9, 463.

NAGA, M., BAN, T., and KUROTSU, T. (1951). Med. J. Osaka Univ., 2, 87.

von SallmanN, L., and Lowenstein, O. (1955). Amer. J. Ophthal., 39, No. 4, pt. 2, p. 11.

SCHMERL, E., and STEINBERG, B. (1950). Ibid., 33, 1379.

THIEL, R. (1952). Büch Augen, Suppl. 21 Klin. Mbl. Augenheilk, p. 9. 